\title{
A Simplified Approach for the Seismic Analysis of Masonry Structures
}

\author{
R. Sabatino and G. Rizzano*
}

Department of Civil Engineering, University of Salerno - Italy

\begin{abstract}
The strongly inelastic behaviour of masonry panels makes inadequate any kind of linear static analyses, and for this reason, both for academic and practical purposes, engineers have to deal with non-linear analyses of masonry buildings. On top of that, the need for non-linear static procedures (NSP) also arises as a consequence of the performancebased earthquake engineering concepts, that generally require the comparison of the seismic demand with the building capacity, expressed in terms of displacements. Within this framework, the choice of the appropriate models to use is fundamental matter: on one hand, the need for accurate predictions of the structural response leads to the adoption of very complex FEM models but, on the other and, the high computational skills and the very time-consuming analyses suggest the adoption of simplified models, such as the equivalent frame approach.

The equivalent frame models are not novel for the analysis of masonry structures, but the actual potentialities have not yet been completely studied, particularly for non-linear applications. In the present paper an effective tool for the non-linear static analysis of 2D masonry walls is presented, namely the software FREMA (Equivalent Frame Analysis of Masonry Structures) developed by the authors.

In this work, the main innovative features of the proposed model (spread plasticity approach, displacement-driven loading process, accurate moment-curvature law for piers in rocking, flexural strength of spandrels) are discussed and an extensive validation of the model has been carried out by means of a comparison with experimental tests and accurate FEM models available in literature.
\end{abstract}

Keywords: Masonry, Seismic analysis, Equivalent frame model, Pushover analysis, FREMA, FEM.

\section{INTRODUCTION}

In recent years, the adoption of performance-based earthquake engineering concepts has led to the application of a number of non-linear static procedures in the seismic assessment of buildings such as the coefficient method [1], the capacity spectrum method [2, 3] and the N2 method [4]. This kind of approach generally requires the comparison of the seismic demand with the building capacity, expressed in terms of displacements. This comparison can be obtained by idealizing the actual building response with an equivalent single-degree-of-freedom (SDOF) oscillator. Within this framework, the assessment of structures can be achieved by means of a non-linear static analysis (pushover analysis), in which the structure undergoes a distribution of increasing lateral loads describing the seismic forces and the displacement of a control node is monitored during the loading process.

The choice of a proper model able to perform a pushover analysis of masonry structures is fundamental matter. To date, two approaches have been mainly adopted. The first approach is represented by the finite elements method (FEM). In this case, masonry constitutive elements (units, mortar) are discretized into a number of finite elements; proper constitutive laws are adopted for bricks and mortar,

*Address correspondence to this author at the Department of Civil Engineering, University of Salerno - Italy; Tel. +39 089 964097;

E-mail: g.rizzano@unisa.it taking into account, in a very accurate way, all the nonlinearities involved in the problem. The result of such a model can accurately catch the structural behaviour of masonry panels, highlighting the damage mechanisms occurred during the loading process. Nevertheless, at the current state of knowledge, this kind of approach has been often applied to masonry panels rather than to whole buildings, due to the high computational effort required by accurate models, which can make their adoption unsustainable for professional practice. On top of that, FEM models suffer from some issues like the potential mesh-dependency, the large number of input parameters (which are not always available for the typical engineering applications) and the request of highly-specialized practitioners.

A second approach is based on the adoption of "equivalent frames", a model very appealing to structural engineers. The structure is idealized as an assemblage of vertical and horizontal elements: the first ones (piers) are the vertical resistant elements for both gravity loads and seismic forces; the horizontal ones (spandrels) are secondary elements which couple the piers in case of seismic loads. Piers and spandrels are connected by rigid offsets and each element is modelled by proper constitutive laws. This approach clearly introduces strong simplifications, and thus its accuracy depends on the consistency between the adopted hypotheses and the actual structural problem.

From these preliminary picture, it is clear that the choice between accurate and simplified models should be obtained as a balanced compromise between accuracy and complexity 
of models, and in some cases (for instance in the vulnerability assessment of a large stock of existing buildings) the adoption of FEM models becomes unsustainable from the practical point of view and so the equivalent frame model can be an effective alternative, provided that the main hypotheses are carefully investigated.

Within this framework, this paper makes a contribution to the seismic analysis of masonry buildings by proposing the computer code FREMA (FRame Equivalent Masonry Analysis) [5-7], devoted, at the current state of development, to the non-linear static analysis of masonry walls undergoing both dead and seismic loads.

\section{THE COMPUTER CODE FREMA}

\subsection{Description of the Proposed Model}

The equivalent frame approach is not a novel application in the field of seismic analysis of masonry buildings. Starting from the POR method developed by [8] in the late seventies, many authors proposed refined versions of this kind of approach $[9,10]$. Nevertheless, the actual potentialities of this kind of approach have not been yet extensively studied, especially in the context of non-linear applications.

Given that, the FREMA code is herein described, by underlining the main features and the main assumptions at the base of the model. The model is able to obtain the forcedisplacement curves of masonry 2D walls undergoing both gravity and seismic loads. The approach is based on the assumption that a perforated $2 \mathrm{D}$ wall can be regarded as a proper assemblage of vertical (piers) and horizontal elements (spandrels), connected by means of rigid offsets.

The model is hence able to describe any kind of perforated wall, though a certain regularity of openings distribution (which is generally found, however, in masonry buildings) is advisable.

The analysis is carried out under displacement control, as this is the only way to catch softening branches in the forcedisplacement curves.

In the equivalent frames models proposed so far, the nonlinear behaviour of piers and spandrels is typically characterized by a concentrated plasticity approach, i.e. flexural plastic hinges are inserted at both sides of the elements and shear plastic hinges are inserted at mid-points.

In this work a smeared non-linearity approach has been adopted: each element (pier/spandrel) is divided into a certain number of slices with homogeneous cross-sections: this approach somehow corresponds to the well-known fibers discretization, but its application is quite an innovation in the framework of equivalent frame models. Forces and displacements are monitored at the centroid of each slice. The overall behaviour of the element is obtained by properly combining the contribution of each slice, modelled by its own constitutive laws, as will be described in the following.

\subsection{Rigid Offset Extension}

The presence of rigid offsets is a feature deriving from the phenomenological observation of the damage of masonry walls after seismic events; such rigid nodes account for the deformability of the masonry in the intersection between piers and spandrels; as the extension of rigid offsets has an important influence on the overall stiffness of walls, some proposals have been made so far, considering different "effective" heights of piers and "effective" length of spandrels. In this work the extension of rigid offsets follows the proposal made in [11].

\subsection{Modelling of Piers}

In the proposed model all the piers collapse mechanisms (Fig. 1) have been considered and a biaxial interaction between axial forced and bending moment $(N-M)$ and axial forces and shear forces $(N-V)$ have been taken into account.
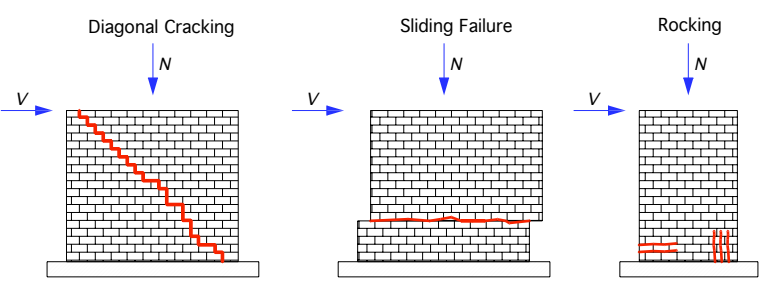

Fig. (1). Piers collapse mechanisms: diagonal cracking, sliding and bending failure/rocking.

\subsection{Flexural Behaviour}

The flexural behaviour of piers has been expressed in terms of a moment-curvature relationship, starting from the uniaxial compressive stress-strain law (Fig. 2):

$$
\frac{\sigma}{\sigma_{d}}=A \frac{\varepsilon}{\varepsilon_{d}}+B\left(\frac{\varepsilon}{\varepsilon_{d}}\right)^{C}
$$

where $\sigma$ is the compressive stress corresponding to the strain $\varepsilon, \sigma_{\mathrm{d}}$ is the maximum strength and $\varepsilon_{\mathrm{d}}$ the corresponding strain. In eq. (1) $A, B$ and $C$ are shape coefficients, which can be obtained, for instance, by fitting the results of experimental data. In this work the values generally adopted for the coefficients are $A=2, B=-2, C=2$ according to [12] while $\varepsilon_{\mathrm{d}}$ is typically included in the range $2.0-3.5 \%$.

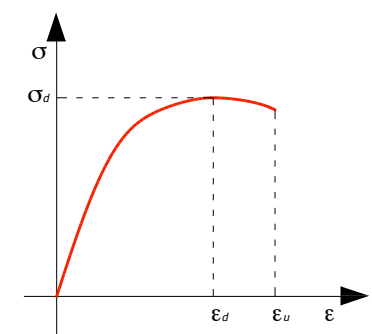

Fig. (2). Compressive stress-strain relationship.

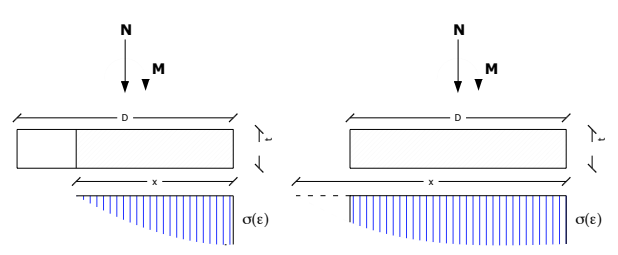

Fig. (3). Uncracked and cracked masonry panel cross-section. 
If an homogeneous cross-section of thickness $t$ and length $D$ is considered (Fig. 3), starting from the stress-strain relationship expressed in eq. (1), the relations between the curvature $\chi$ and $M$ (the bending moment) and $N$ (the axial force) can be obtained by considering the equilibrium equations and the deformation compatibility equation, both for uncracked and cracked section:

\subsubsection{Uncracked Section}

$$
\begin{aligned}
& v=k_{1}(2 \xi-1)+k_{2}\left[\xi^{C+1}-(\xi-1)^{C+1}\right] \\
& \mu=k_{1}\left(\frac{1}{2}-\xi\right)(2 \xi-1)+\frac{2}{3} k_{1}\left[\xi^{3}-(\xi-1)^{3}\right]+ \\
& +k_{2}\left(\frac{1}{2}-\xi\right)\left[\xi^{C+1}-(\xi-1)^{C+1}\right]+k_{2} \frac{C+1}{C+2}\left[\xi^{C+2}-(\xi-1)^{C+2}\right]
\end{aligned}
$$

$$
\mu=k_{1}\left(\frac{1}{2}-\xi\right) \xi^{2}+\frac{2}{3} k_{1} \xi^{3}+k_{2}\left(\frac{1}{2}-\xi\right) \xi^{C+1}+k_{2} \frac{C+1}{C+2} \xi^{C+2}
$$

In eq. (2-5) $\xi=x / D$ is the normalised neutral axis, $v=N / D t \sigma_{\mathrm{d}}$ is the normalised uniaxial stress, $\mu=N / D t^{2} \sigma_{\mathrm{d}}$ is the normalised bending moment, $k_{1}$ and $k_{2}$ are two coefficients depending on the curvature $\chi$ :

$$
k_{1}=\frac{A}{2}\left(\frac{\chi D}{\varepsilon_{d}}\right)
$$

Starting from the set of equations (2-5), the momentcurvature law of each slice can be described and thus the overall flexural behaviour of piers can be derived (Fig. 4). The collapse condition corresponds to the attainment of the ultimate curvature $\chi_{\mathrm{u}}$ (which, in turn, corresponds to the attainment of the ultimate strain $\varepsilon_{\mathrm{u}}$ in the extreme fibre of the cross-section).

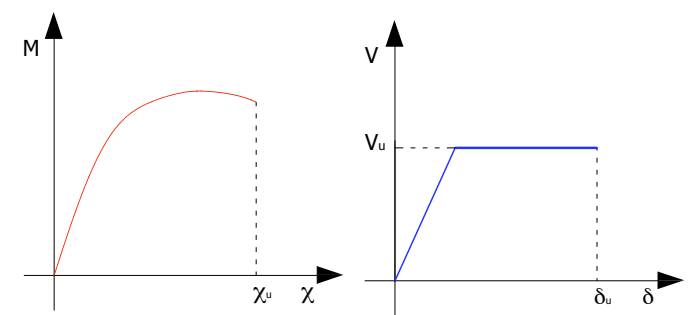

Fig. (4). Moment-curvature and shear-displacement curves adopted for piers modelling.

\subsection{Shear Behaviour}

The shear behaviour of piers has been modelled as elastic-plastic (Fig. 4), with ultimate shear $V_{\mathrm{u}}$ obtained as the minimum between the failure for diagonal cracking $V_{\mathrm{d}}$ and the failure for sliding $V_{\mathrm{s}}$ (Fig. 1), as summarized in Table (1). Diagonal cracking has been modelled both for irregular masonry piers $[13,14]$ and for brick-made masonry piers [15].

In Eq. (7-9), $t$ is the pier thickness, $D$ the pier length, $c$ the cohesion, $\mu$ the friction coefficient, $p$ the average compressive stress, $\alpha V=M / V N$ the shear coefficient, $f_{\text {tu }}$ the con- ventional tensile strength of masonry, $b$ a coefficient depending on the geometry of the pier, and $\bar{c}=c /(1+\mu \varphi)$

\begin{tabular}{|c|c|c|}
\hline & $\begin{array}{c}\text { Brick-Made Masonry } \\
\text { Piers }\end{array}$ & Irregular Masonry Piers \\
\hline 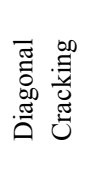 & $\begin{array}{l}V_{d}=D t \min \left\{\tau_{j} ; \tau_{b}\right\} \\
\text { with } \tau_{j}=\bar{c}+\bar{\mu} p \\
\tau_{b}=\frac{f_{b t}}{2.3} \sqrt{1+\frac{p}{f_{b t}}}\end{array}$ & $\begin{array}{l}V_{d}=D t \tau_{d} \\
\text { with } \tau_{d}=\frac{f_{t u}}{b} \sqrt{1+\frac{p}{f_{t u}}}\end{array}$ \\
\hline$\stackrel{\infty}{:}$ & $V_{s}=D t \tau_{s}$ with $\tau$ & $\frac{1.5 c+\mu p}{1+3 \frac{c \alpha_{v}}{p}}$ \\
\hline
\end{tabular}
$\bar{\mu}=\mu /(1+\mu \varphi)$ are "reduced" cohesion and friction coefficient (depending on the interlocking parameter $\phi=2 \Delta y / \Delta x$, being $\Delta x$ and $\Delta y$ the brick dimensions).

Table 1. Shear Resistance of Piers

The shear collapse corresponds to the attainment of the ultimate drift $\delta_{\mathrm{u}}$ (Fig. 4), which can be assumed, according to the Italian Building Code [16], to the $0.4 \%$ of the effective height of the pier.

\subsection{Modelling of Spandrels}

The behaviour of spandrels is a major issue in equivalent frame models. Spandrels, in fact, play a fundamental role in the seismic behaviour of masonry walls, as they determine the coupling between piers and the piers boundary conditions.

Unfortunately, while many experimental results (shearcompression tests, diagonal compression tests, etc.) are available for piers, even under cyclic loads, to date very few tests have been carried out to study the experimental behaviour of spandrels. Such experimental outcomes are of paramount importance to define the spandrels response, which is considerably different from that of vertical elements because under seismic loads, the spandrels are subjected to shear and bending and, most important, they are subjected to negligible axial force.

Spandrels collapse typically occurs according to two mechanisms: rocking and diagonal cracking. Sliding failure, in fact, cannot occur due to the interlocking phenomena originated at the interface between the end-sections of spandrels and the adjacent piers; crushing cannot occur given the very low axial forces acting.

\subsection{Flexural Behaviour}

In this model, an elastic-plastic relation is proposed for flexural behaviour of spandrels (Fig. 5). The evaluation of the ultimate bending moment represents a crucial issue in equivalent frame modelling. Due to the lack of experimental data, it can be worth reviewing the current formulations proposed by some national codes, such as the Italian Building Code, in which two different cases are examined: spandrels 
with axial force known or unknown, as summarized in Table 2, where the corresponding spandrel flexural resistance is also given.

Table 2. Rocking Resistance of Spandrels According to Italian Building Code

1. The axial force $N$ acting on the spandrels is known $\rightarrow$ Spandrels can be regarded as $90^{\circ}$-rotated piers; $h$ is the spandrel height, $t$ the spandrel thickness, $\kappa=0.85$ for rectangular stress block distribution, $f_{d}$ is the compressive strength of masonry in vertical direction.

$$
M_{u}=\frac{N h}{2}\left(1-\frac{N}{\kappa f_{d} h t}\right)
$$

2 . The axial force $N$ acting on the spandrels is not known $\rightarrow$ $H_{p}$ is the minimum between the tensile strength of a resistant element (such as a r.c. ring beam or a tie rod) and $0.4 f_{h d} h t$, where $f_{h d}$ is the compressive strength of masonry in horizontal direction.

$$
M_{u}=\frac{H_{p} h}{2}\left(1-\frac{H_{p}}{\kappa f_{h d} h t}\right)
$$

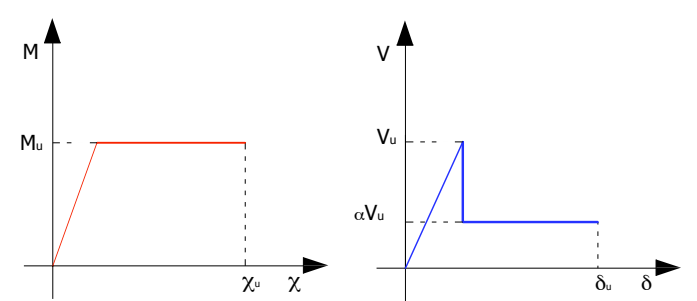

Fig. (5). Moment-curvature and shear-displacement curves adopted for spandrels modelling.

It is interesting to observe that, according to eq. (11), if the spandrel is not provided with a steel tie or a r.c. ring beam, no rocking resistance is available. Conversely, according to eq. (10), where spandrels are regarded as a $90^{\circ}$-rotated piers, a stress-block distribution of stresses is adopted, but this leads to very low rocking strength, due to the very low values of $\mathrm{N}$ acting on the spandrels.

It is clear that this kind of approach leads to very conservative results and strong underestimations of the wall actual capacity.

For this reason, a simplified model for describing brickmade spandrels flexural behaviour has been considered in the code FREMA. Such model was first studied in $[17,18]$ and then has been applied in [19] where some comparisons with accurate FEM simulations have been also carried out.

The model assumes that, due to interlocking phenomena between bed and collar joints at the interface between piers and spandrels, an equivalent strut, provided with an "equivalent" tensile strength can develop. Such a strength only applies to the spandrels.

In order to evaluate the equivalent tensile strength $f_{\text {tu }}$, two failure mechanism are taken into account (Fig. 6): 1) tensile failure of bricks; 2) shear failure of bed joints. The model assumes negligible mechanic parameters for the head joints, uniform tensile stress along the spandrel, uniform shear stress distribution along the bed joints, joint thickness negligible if compared to the brick dimension $\Delta y$.

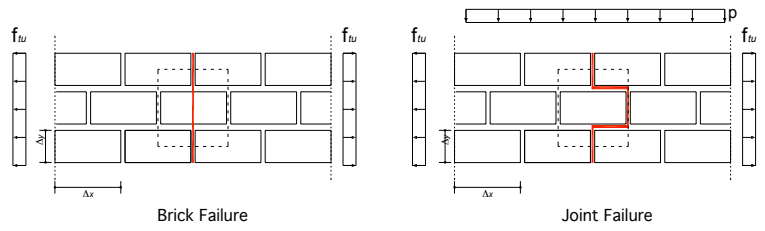

Fig. (6). Spandrel failure mechanisms.

Starting from these assumptions, and considering a reference volume as depicted in Fig. (6), the two collapse mechanisms lead to the following expressions for $f_{\mathrm{tu}}$ :

$$
\begin{aligned}
& f_{t u, 1}=\frac{f_{b t}}{2} \\
& f_{t u, 2}=(c+\mu \bar{p}) \frac{\Delta x}{2 \Delta y}=\frac{c+\mu \bar{p}}{\varphi}
\end{aligned}
$$

Finally, the equivalent tensile strength is the minimum between the two mechanisms: $f_{\mathrm{tu}}=\min \left\{f_{\mathrm{tu}, 1} ; f_{\mathrm{tu}, 2}\right\}$.

In eq. (13) $\bar{p}$ can be assumed as the $65 \%$ of the average normal stress acting on the adjacent piers, as suggested in [19].

The introduction of a spandrel tensile strength, even low, gives rise to a significant improvement in terms of rocking resistance. In fact, assuming an elasto-plastic constitutive law both in tension and compression (Fig. 7), (where $\mu_{\mathrm{c}}$ is the ductility in compression, $\mu_{\mathrm{t}}=\infty$ is the ductility in tension, $\eta$ is the ratio between the compressive strength $f_{\mathrm{d}}$ and the equivalent tensile strength $f_{\text {tu }}$ ) and developing the equilibrium equations of the spandrel cross-section, the limit domain $(M-N)$ is significantly improved. An example of limit domain $(M-N)$ is depicted in Fig. (8), obtained for $\eta=0.1$, $\mu_{\mathrm{c}}=1.18, \mu_{\mathrm{t}}=\infty, N_{\text {lim }}=h t f_{\mathrm{d}}, M_{\text {lim }}=h t^{2} f_{\mathrm{d}} / 4$. The most interesting result is represented by the presence of a flexural resistance also with low or even with no axial force; such effect represents a striking difference if compared to eq. (10), depicted in the same figure.

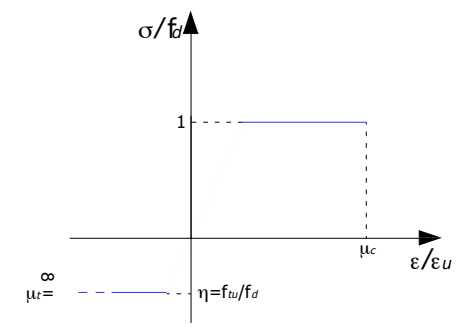

Fig. (7). Spandrel elasto-plastic constitutive law.

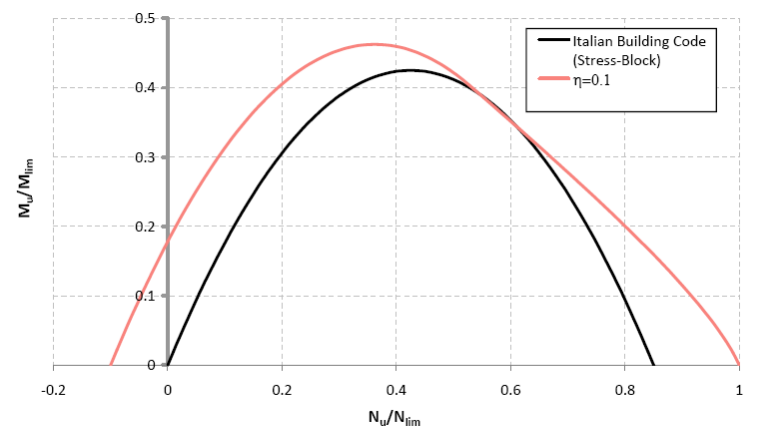

Fig. (8). Limit Domain $(N-V)$. 


\subsection{Shear Behaviour}

The shear behaviour of spandrel has been modelled as elastic-fragile with residual strength, as depicted in Fig. (5). The ultimate shear strength is expressed as:

$$
V_{u}=h t f_{v d}
$$

being $h$ and $t$ respectively the spandrel height and thickness, and fvd the cohesion of the mortar bed joints. In the present work, the residual strength has been generally assumed as $25 \%$ of $V_{\mathrm{u}}(\alpha=0.25)$, although recent experimental studies [20] suggest higher values for the residual strength.

\section{PRELIMINARY VALIDATION OF THE MODEL}

The model herein described has been validated by means of a series of comparisons with experimental tests, accurate FEM models and other equivalent frame models. For all the comparisons described in this section, the mechanical properties adopted in the analyses are summarized in Table $\mathbf{3}$.

Table 3. Mechanical Properties Adopted in the Numerical Analyses

\begin{tabular}{|c|c|c|c|c|c|c|}
\hline & & & 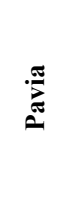 & 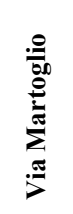 & 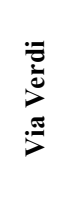 & 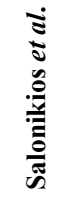 \\
\hline \multicolumn{7}{|c|}{ Masonry } \\
\hline $\begin{array}{l}\text { Young's } \\
\text { modulus }\end{array}$ & $E$ & {$[\mathrm{MPa}]$} & 1400 & 1600 & 1500 & 1650 \\
\hline $\begin{array}{l}\text { Shear } \\
\text { modulus }\end{array}$ & $G$ & {$[\mathrm{MPa}]$} & 480 & 300 & 250 & 660 \\
\hline $\begin{array}{l}\text { Compres- } \\
\text { sive strength }\end{array}$ & $f_{w c}$ & {$[\mathrm{MPa}]$} & 6.20 & 6.00 & 2.40 & 3.00 \\
\hline $\begin{array}{l}\text { Shear } \\
\text { Strength }\end{array}$ & $f_{v d 0}$ & {$[\mathrm{MPa}]$} & 0.18 & 0.16 & 0.13 & 0.10 \\
\hline \multicolumn{7}{|c|}{ Brick Units } \\
\hline $\begin{array}{l}\text { Tensile } \\
\text { Strength }\end{array}$ & $f_{b t}$ & {$[\mathrm{MPa}]$} & 1.22 & 1.00 & 2.00 & 1.00 \\
\hline \multicolumn{7}{|c|}{ Mortar joints } \\
\hline Cohesion & $c$ & [MPa] & 0.23 & 0.15 & 0.20 & 0.10 \\
\hline $\begin{array}{l}\text { Friction } \\
\text { coefficient }\end{array}$ & $\mu$ & - & 0.58 & 0.50 & 0.50 & 0.58 \\
\hline
\end{tabular}

3.1. Experimental Test at University of Pavia: Pavia Door Wall $[21,22]$

A very detailed experimental test has been carried at the University of Pavia, Italy [21, 22]. A full scale, two-storey URM building prototype (plan dimension $6.00 \times 4.40 \mathrm{~m}$ ) has been tested by applying cyclic displacements at floor levels (Fig. 9), such to obtain a distribution of lateral forces proportional to seismic weights (in addition to gravity loads: 248.8 $\mathrm{kN}$ at first floor, $236.8 \mathrm{kN}$ at second floor). The prototype contains an almost independent shear wall ("Pavia Door Wall") which has been an interesting benchmark for many authors $[23,24]$.
In Fig. (10) the comparison between the code FREMA and the experimental test is depicted. In the same figure, the predictions of some models - such as the SAM code [9], the TREMURI software [24] and an accurate FEM simulation [23] - is also depicted. The comparison show a satisfactory agreement between the experimental test and the proposed code; moreover a general agreement with all the models is present. The slight strength overestimation provided by all the theoretical models can be easily explained considering that the experimental curve is the monotonic envelope of a cyclic curve, and thus it represents the lower bound of the actual monotonic response. The figure also depicts the forcedisplacement curve of the wall obtained applying the spandrel flexural behaviour proposed in the Italian Building Code; in that case the prediction clearly underestimates both the actual strength and the stiffness of the wall.

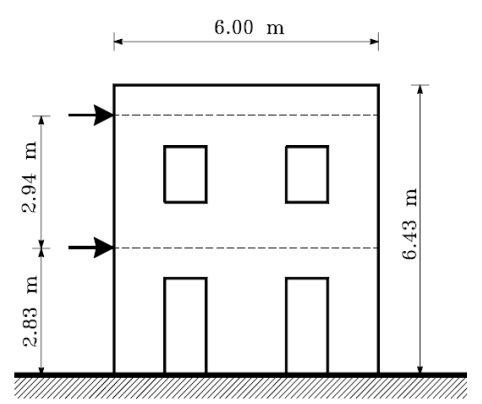

Fig. (9). Pavia Door Wall testing scheme.

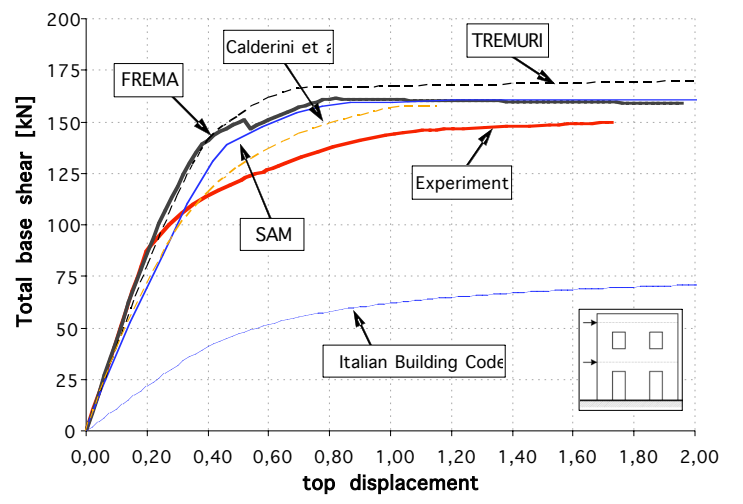

Fig. (10). Total base shear vs. top displacement curves: Pavia Door Wall.

\subsection{Numerical Simulations: Catania Project [25]}

The Catania Project [25] - an Italian nationwide research project aimed at evaluating the seismic performance of two existing masonry buildings - provided a series of numerical simulations carried out by several research groups (R.G.) of different Italian universities.

The aim of the project was to compare several strategies of modelling, in order to highlight the main differences between the models: the Pavia R.G. used the SAM code [26], which is an equivalent frame approach; Genoa R.G. simulations were obtained by applying an accurate FEM model [27]; finally the Basilicata R.G. model was performed by 
means of a no-tensile strength macro-element with shear failure and crushing control [28].

The first analyzed wall (Via Martoglio Wall) was "extracted" from a five-storey building. For this wall, three models have been developed: unreinforced masonry (URM) wall (model 1) and masonry wall with elastic r.c. ring beams $\left(E_{\mathrm{c}}=4000 \mathrm{MPa}\right.$ in model $2, E_{\mathrm{c}}=20000 \mathrm{MPa}$ in model $3, E_{\mathrm{c}}$ is the concrete Young's modulus). Pushover analyses with the vector of lateral load $F=\{1.00,1.92,2.80,3.16,1.00\}$ were performed.

The comparisons between the proposed model and the R.G. results are depicted in Fig. (11-13). The agreement with the SAM code is very satisfactory; a good agreement with the Genoa R.G. is also present in terms of stiffness and residual strength for the unreinforced masonry (URM) wall.

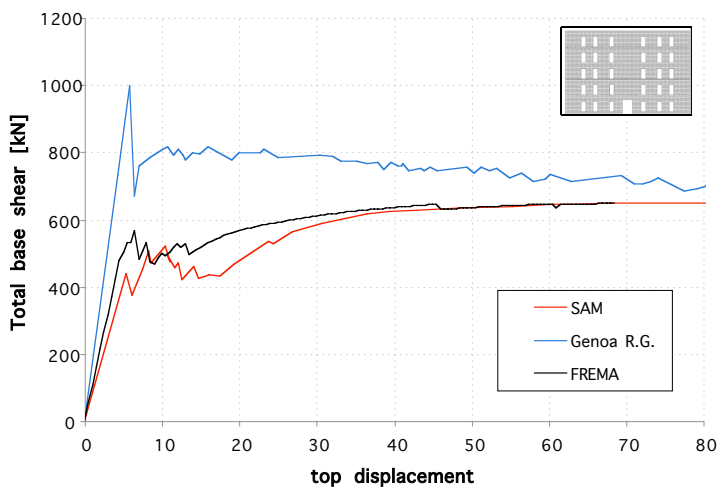

Fig. (11). Total base shear vs. top displacement curves: Via Martoglio wall, Model 1.

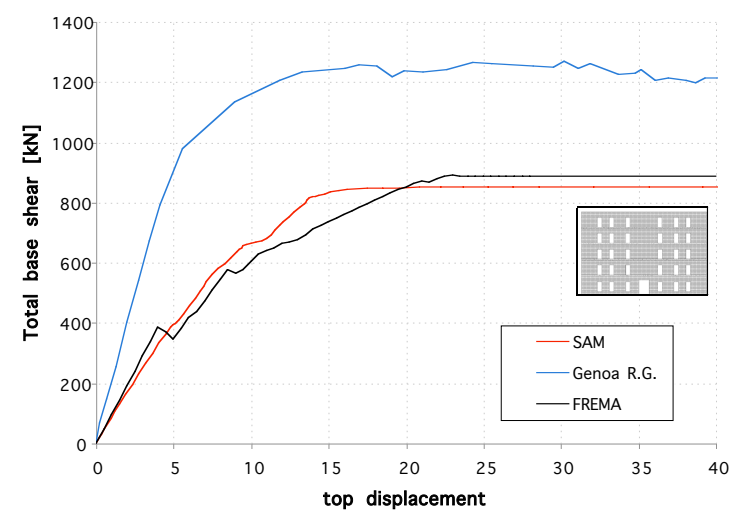

Fig. (12). Total base shear vs. top displacement curves: Via Martoglio wall, Model 2.

Within the same framework of the Catania Project, three more walls, with very different geometrical features, have been analyzed (Via Verdi Walls "A", "B", "D"). In addition to the Italian R.G. results, for walls " $A$ " and "D" standard pushover analyses (hereafter referred to as SPO1 and SPO2) have been performed by [29] with SAP2000® V.10 modelling the walls as equivalent frames. The comparison, depicted in Fig. (14-16), shows a good agreement particularly among the equivalent frame models (SAM, SAP2000, FREMA) whereas the general trend of the Genoa R.G. is characterized by higher values of strength and stiffness. This can be easily explained considering that the elements strength computed within the equivalent frames model are always obtained taking into account a partialization of the cross-section, due to the lack of tensile strength of masonry. The F.E. model, on the contrary, considers a low tensile strength of mortar joints which, even low, can strongly affect the strength of the elements, particularly if the axial stress acting on the elements are quite low.

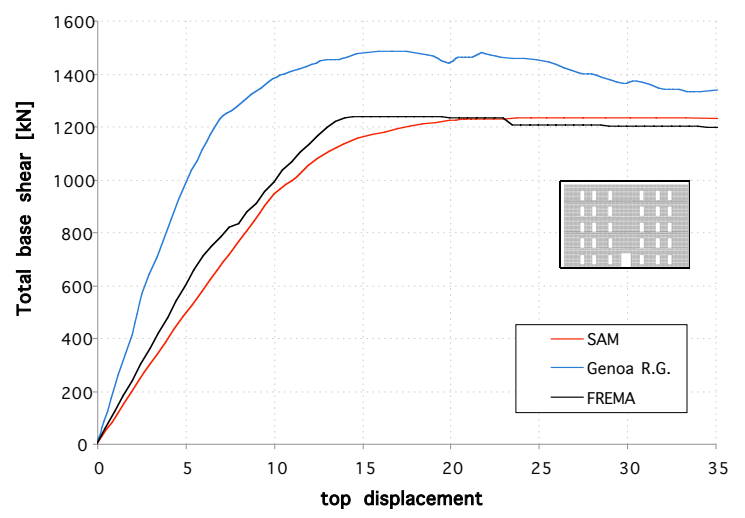

Fig. (13). Total base shear vs. top displacement curves: Via Martoglio wall, Model 3.

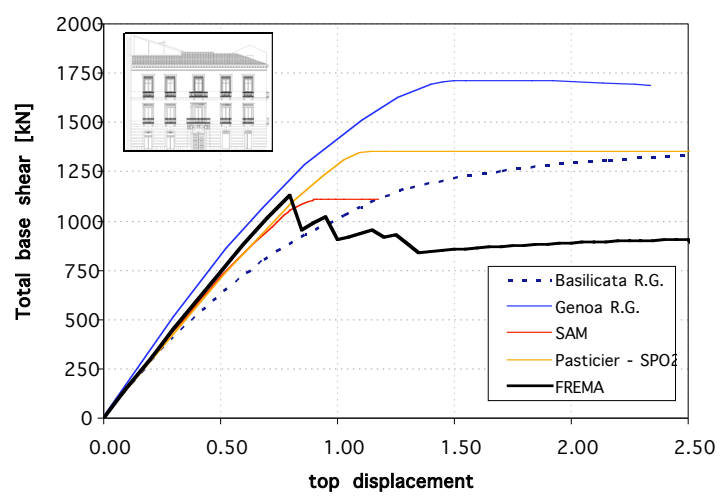

Fig. (14). Total base shear vs. top displacement curves: Via Verdi wall A..

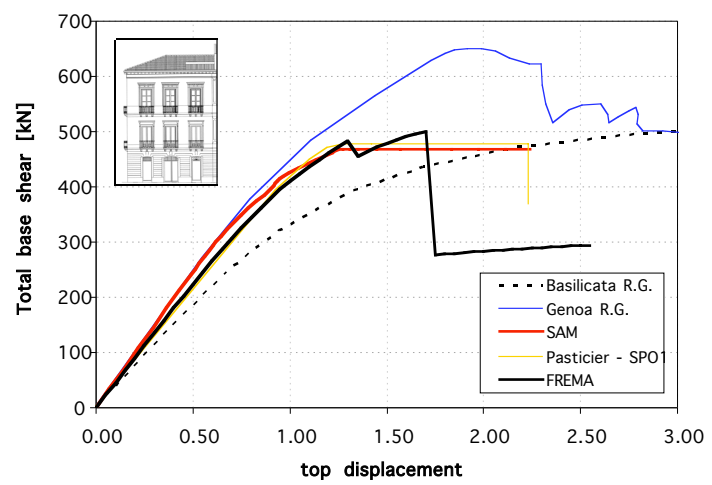

Fig. (15). Total base shear vs. top displacement curves: Via Verdi wall D.

\subsection{Numerical Simulations: Salonikios et al. [30]}

A further validation of the code has been obtained comparing the results provided by FREMA with the analyses of a two-storey, seven-bay masonry wall in-plane loaded. The 
wall has been analyzed in [30] both by means of an equivalent frame model (SAP2000 ${ }^{\circledR}$ ) and by means of a finite elements code $\left(\mathrm{CAST} 3 \mathrm{M}^{\circledR}\right)$. Two different pushover analyses were performed, by applying both a lateral load distribution proportional to seismic weights (Load case ACC; vector of lateral load $F=\{1.00,0.59\})$ and an inverse triangular lateral load distribution (Load case: LOAD; $F=\{1.00,1.19\}$ ). The results of the comparison among the three different models are depicted in Fig. (17-18).

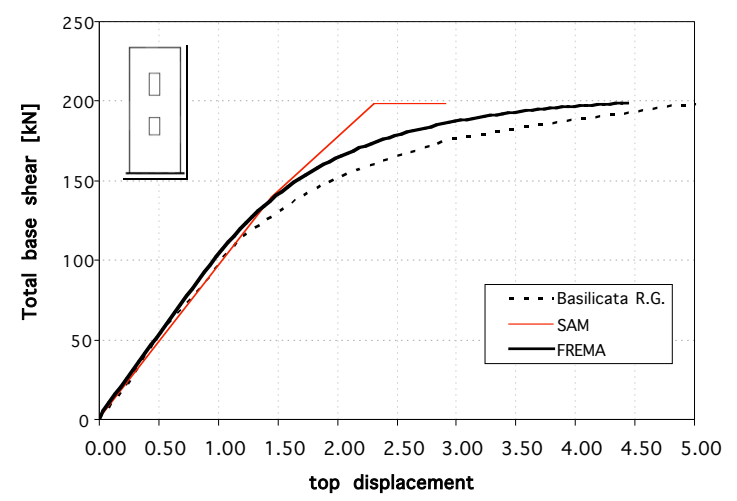

Fig. (16). Total base shear vs. top displacement curves: Via Verdi wall B.

The comparison shows an overall good agreement between the proposed model and both the SAP and the CAST3M predictions in terms of stiffness and peak strength. A relevant aspect is that, while the SAP model does not seem to be affected by the lateral load distribution, in the FREMA code such influence can be clearly found. In particular, the ACC case should lead to a higher stiffness of the frame if compared to the LOAD case, because, while the first-storey piers undergo the same lateral load, the second-storey piers are subjected to a shear much lower in the ACC case, resulting in a lower total displacement at the control node.

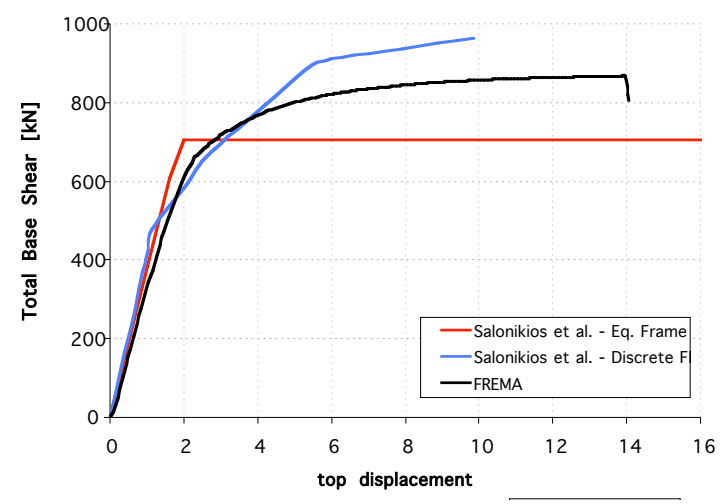

Fig. (17). Total base shear vs. top displacement curves: Salonikios et al., ACC load case.

\subsection{Numerical Simulations: Mallardo et al. [31]}

In [31] the seismic behaviour of a historical palace in Ferrara, Italy (Palazzo Renata di Francia) has been investigated. A pushover analysis has been performed on the Palace façade, a two-storeys and twelve-bays masonry wall (Fig. 19), by means of commercial codes $\left(\right.$ ProSAP $^{\circledR}$ and
$\mathrm{PCM}^{\circledR}$ ), a FEM model (ADINA ${ }^{\circledR}$ ) and limit analysis. Analyses have been performed considering an inverse triangular lateral load distribution. The comparison between the numerical simulations and the FREMA code is depicted in Fig. (20). The comparison clearly shows a very good prediction of the FREMA code, both in terms of stiffness and in terms of strength. It is interesting to observe that the prediction of the commercial codes is quite poor, probably due to the model adopted for spandrels.

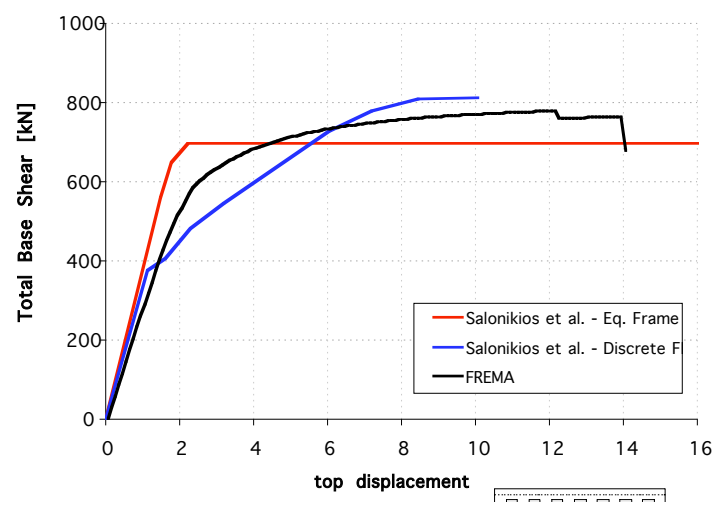

Fig. (18). Total base shear vs. top displacement curves: Salonikios et al., LOAD load case.

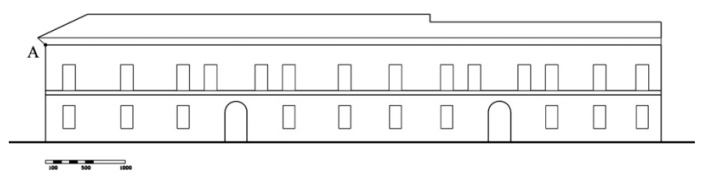

Fig. (19). Palace Renata di Francia façade.

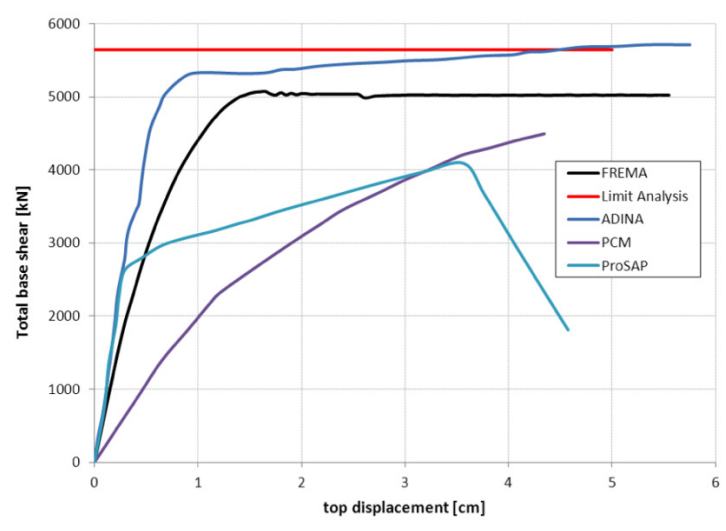

Fig. (20). Total base shear vs. top displacement curves: Palace Renata di Francia façade.

\section{CONCLUSIONS}

In this paper, an equivalent frame model, purposely developed by the authors, has been presented. The code FREMA is able to perform pushover analyses of in-plane loaded masonry walls. The main features of the model, particularly the behaviour of piers and spandrels have been briefly illustrated. A preliminary validation of the code has been carried out, by means of a comparison with experimental tests, accurate FEM simulations and other equivalent frame models available in literature. A satisfactory agree- 
ment between the proposed model and both experimental and numerical results has been found.

\section{ACKNOWLEDGEMENTS}

The authors would like to gratefully acknowledge Eng. G. Torello for the contribution given to the development of the code FREMA.

\section{REFERENCES}

[1] ASCE, Prestandard and Commentary for the Seismic Rehabilitation of Buildings, FEMA 356, American Society of Civil Engineers: Washington D.C., United States, 2000.

[2] ATC, Seismic Evaluation and Retrofit of Concrete Buildings, ATC-40 Report, American Technical Council: Redwod City, United States, 1996.

[3] S. A. Freeman, "The capacity spectrum method as a tool for seismic design", 11th European Conference on Earthquake Engineering, Paris, France, 1998.

[4] P. Fajfar, and M. Fischinger, "N2 - A method for non-linear seismic analysis of regular buildings", 9th World Conference on Earthquake Engineering, Tokyo, Kyoto, Japan, 1988.

[5] G. Rizzano, and R. Sabatino, "Non-linear Static Analysis of Masonry Structures by means of Equivalent Frames Simplified Approach", Proc. of 8th International Masonry Conference, pp. 12111220, Dresden, Germany, 2010

[6] R. Sabatino, and G. Rizzano, Non-linear Static Analysis of Masonry Structures. Simplified Equivalent Frames and accurate models, Proc. of 14th European Conference on Earthquake Engineering, Ohrid, Macedonia, 2010.

[7] R. Sabatino, "Non-Linear Analysis Of Masonry Walls Under Horizontal Loads: Equivalent Frame Modeling”, Ph. D. thesis, University of Salerno, Italy, 2011. (in Italian).

[8] M. Tomazevic, The computer program POR, Report ZMRK, Institute for Testing and Research in Materials and Structures, Ljubljiana, Slovenia, 1978.

[9] G. Magenes, and A. D. Fontana, Simplified non-linear seismic analysis of masonry buildings, 5th International Masonry Conference, Proc. of the British Masonry Society, vol. 8, pp. 190-195, 1998.

[10] G. Penelis, "An efficient approach for pushover analysis of unreinforced masonry (URM) structures", J. Earthquake Eng. vol. 10, no. 3, pp. 359-379, 2006.

[11] M. Dolce, "Schematizzazione e modellazione degli edifici in muratura soggetti ad azioni sismiche (Modelling of masonry buildings under seismic loads)", L'Industria delle Costruzioni, vol. 242, pp. 44-57, 1991. (in Italian).

[12] A. W. Hendry, Structural Masonry (2nd ed.), New York: Macmillan, 1998.

[13] V. Turnsek, and F. Cacovic, "Some experimental results on the strength of brick masonry walls", Proc. of the 2nd International Brick Masonry Conference, 149-156, Stoke on Trent, UK, 1970.

[14] V. Turnsek, and P. Sheppard, "The shear and flexural resistance of masonry walls", Proc. of the International Research Conference on Earthquake Engineering, 517-573, Skopje, Macedonia, 1980.

[15] W. Mann, and H. Muller, "Failure of shear stressed masonry - An enlarged theory, tests and application to shear-walls", Proceedings of the International Symposium on Load-Bering Brickwork, 223235, London, UK, 1980.
[16] M.I.T, D.M. 14.01.2008. Norme Tecniche per le Costruzioni, Ministero Infrastrutture e Trasporti: Rome, Italy, 2008. (in Italian).

[17] D. Kasten, and P. Schubert, "Verblendschalen aus Kalksandsteinen: Beanspruchung, rissfreie Wandlange", Hinweise zur Ausführung, Bautechnik, vol. 3, pp. 86-94, 1985. (in German).

[18] P. Schubert, and K. Weschke, Verformung und Risssicherheit von Mauerwerk, Mauerwerk-Kalender, Ernst \& Sohn Ed., 145-159, Berlin, Germany, 1986. (in German).

[19] S. Cattari, and S. Lagomarsino, "A strength criterion for the flexural behaviour of spandrels in un-reinforced masonry walls", Proc. of 14th World Conference on Earthquake Engineering, Beijing, China, 2008 .

[20] N. Gattesco, L. Macorini, I. Clemente, and S. Noe, "Shear resistance of spandrels in brick masonry buildings", Proc. of 8th International Masonry Conference, pp. 2119-2130, Dresden, Germany, 2010.

[21] G. M. Calvi, and G. Magenes, "Experimental research on response of URM building system", in D. P. Abrams, G. M. Calvi eds., Proc. U.S. - Italy workshop on guidelines for seismic evaluation and rehabilitation of unreinforced masonry buildings, State University of New York at Buffalo, NCEER-94-0021, 3-41/57, Pavia, Italy, 1994.

[22] G. Magenes, G. M. Calvi, and G. R. Kingsley, Seismic Testing of a Full-Scale, Two-Story Masonry Building: Test Procedure and Measured Experimental Response, in Experimental and Numerical Investigation on a brick Masonry Building Prototype - Numerical Prediction of the Experiment, Report 3.0 - G.N.D.T., Pavia, Italy, 1995.

[23] C. Calderini, S. Cattari, and S. Lagomarsino, "In-plane strength of unreinforced masonry piers", Earthquake Eng. Struct. Dyn. vol. 38, pp. 243-267, 2009.

[24] A. Galasco, S. Lagomarsino, and A. Penna, TREMURI Program: Seismic Analyser of 3D Masonry Bulidings, University of Genoa, Italy, 2002.

[25] D. Liberatore, Progetto Catania: Indagine sulla risposta sismica di due edifici in muratura (Project Catania: Investigation on the seismic response of two masonry buildings). GNDT - National Group for Seismic Protection: Rome, 2000. (in Italian).

[26] G. Magenes, D. Bolognini, and C. Braggio, C. Metodi semplificati per l'analisi sismica non lineare di edifici in muratura (Simplified Methods for the non-linear seismic analysis of masonry buildings), GNDT - National Group for Seismic Protection: Rome, Italy, 2000. (in Italian).

[27] L. Gambarotta, and S. Lagomarsino, "Damage models for the seismic response of brick masonry shear walls. Part II: the continuum model and its application", Earthquake Eng. Struct. Dyn. vol. 26, no. 4, pp. 441-462, 1997.

[28] F. Braga, and D. Liberatore, "A finite element for the analysis of the response of masonry buildings", Proc. of the 5th North American Masonry Conference, Urbana, United States, 1990.

[29] L. Pasticier, C. Amadio, and M. Fragiacomo, "Non-linear seismic analysis and vulnerability evaluation of a masonry building by means of the SAP2000 v.10 Code", Earthquake Eng. Struct. Dyn.vol. 37, pp. 467-485, 2008.

[30] T. Salonikios, C. Karakostas, V. Leikidis, and A. Anthoine, "Comparative inelastic pushover analysis of masonry frames", Earthquake Eng. Struct. Dyn.vol. 25, pp. 1515-1523, 2003.

[31] V. Mallardo, R. Malvezzi, E. Milani, and G. Milani, "Seismic vulnerability of historical masonry buildings: A case study in Ferrara", Eng. Struct. vol. 30, pp. 2223-2241, 2008.

(C) Sabatino and Rizzano; Licensee Bentham Open.

This is an open access article licensed under the terms of the Creative Commons Attribution Non-Commercial License (http://creativecommons.org/licenses/by-nc/3.0/) which permits unrestricted, non-commercial use, distribution and reproduction in any medium, provided the work is properly cited. 